\title{
Prognostic significance of alpha frequency EEG rhythm in coma after cardiac arrest
}

\author{
K URT T ØRENSEN, A N E THOMASSEN, \\ A N D MOGENS WER NBERG \\ From the Departments of Clinical Neurophysiology and Anaesthesiology, University Hospital, \\ Arhus, Denmark
}

S U M MARY Sixty-five patients who remained in coma for more than 24 hours after resuscitation from cardiac arrest were divided into two groups according to their EEGs. Thirteen patients were found to have rhythm of alpha frequency while 52 had the usual EEG findings after cerebral anoxia. Three patients from the group with alpha frequency EEG rhythms regained full consciousness but showed severe sequelae. Our results suggest that the prognosis of comatose patients with EEG rhythm of alpha frequency is no poorer than that of other individuals who are comatose after cardiac arrest.

Only recently have there been reports of alpha activity as the dominant EEG pattern of comatose patients after cardiac arrest. This combination of a clinical state of coma and an EEG pattern resembling the normal waking EEG with alpha activity has been called "alpha-coma" (Vignaendra et al., 1974; Sharbrough et al., 1975; Westmoreland et al., 1975). These first reports indicated that such a finding carried an extremely bad prognosis. However, that this is not always the case is suggested by a paper by Chokroverty (1975) who described two patients who survived "alpha-coma" with only minimal brain damage.

In this paper we describe the clinical and EEG findings in 13 patients with alpha frequency EEG rhythm in coma after cardiac arrest, and compare the outcome in these patients with that in 52 individuals who differed only electroencephalographically from the patients with "alpha-coma."

\section{Patients and methods}

Our sample includes 65 patients who had such severe brain anoxia after cardiopulmonary arrest that they remained in coma for more than 24 hours after resuscitation. All the patients were admitted to Århus Kommunehospital intensive care unit during a period of five years. All patients with primary neurological diseases, poisonings, and

Address for reprint requests: Dr K. Sørensen, Department of Neurology, University Hospital, DK-8000 Århus, Denmark.

Accepted 7 May 1978 severe endocrine disturbances have been excluded. Children below the age of 15 years have also been excluded.

Cardiac arrest was verified in all patients by electrocardiography. The causes and duration of anoxia are indicated in Tables 1 and 2. All EEGs were carried out on an 8-channel Kaiser apparatus, using 18 scalp electrodes applied according to the international 10-20 system. Bipolar and referential derivations were used for at least 30 minutes. Most of the initial EEG recordings were made within

Table 1 Causes of anoxia in 65 patients in coma after cardiac arrest

\begin{tabular}{llcr}
\hline Diagnoses & $\begin{array}{l}\text { With } \\
\text { alpha-coma }\end{array}$ & $\begin{array}{l}\text { Without } \\
\text { alpha-coma }\end{array}$ & Total \\
\hline Acute myocardial infarct & 8 & 30 & 38 \\
Other heart disease & 3 & 5 & 8 \\
Acute respiratory failure & 1 & 11 & 12 \\
Intra- or postoperative arrest & 1 & 4 & 5 \\
Other & 0 & 2 & 2 \\
Total & 13 & 52 & 65 \\
\hline
\end{tabular}

Table 2 Duration of anoxia in 65 patients in coma after cardiac arrest

\begin{tabular}{lccc}
\hline $\begin{array}{l}\text { Estimated duration } \\
\text { of anoxia (min) }\end{array}$ & $\begin{array}{l}\text { With } \\
\text { alpha-coma }\end{array}$ & $\begin{array}{l}\text { Without } \\
\text { alpha-coma }\end{array}$ & Total \\
\hline$<5$ & 6 & 17 & 23 \\
$5-10$ & 1 & 7 & 8 \\
$>10$ & 2 & 5 & 7 \\
Unknown & 4 & 23 & 27 \\
Total & 13 & 52 & 65 \\
\hline
\end{tabular}


the first 24 hours after cardiac arrest, when all patients were in coma. On the basis of the EEG findings the sample was divided into two groups. One consisted of 13 patients with EEG rhythms of alpha frequency, and the other of 52 individuals whose EEGs showed changes typical of cerebral anoxia, as described by Pampiglione (1962).

\section{Results}

Of the 13 patients with EEG rhythms of alpha frequency, 10 died between two and 289 days after cardiac arrest. The average period of survival was 81.9 days. All these 10 patients remained in coma till death. Three patients regained full consciousness but one of these died 23 days later from a further cardiac arrest.

Of the other 52 patients, 48 died between one and 108 days after cardiac arrest. The average period of survival was $\mathbf{1 5 . 6}$ days. One patient regained consciousness but died 14 days later from a further cardiac arrest. At the end of the investigation three patients in this group were alive. One was still in coma after a year, and two were conscious but had severe neurological sequelae and required continued hospitalisation. It is important to note here that the causes of death of the 10 patients with coma associated with alpha frequency EEG rhythms were cardiac complications or pneumonia. None of these patients developed clinical signs of brain death.

\section{CASE REPORTS}

The cases described are the three surviving patients from the group with EEG alpha frequency waves.

\section{Case 1}

This sixteen year old male was in coma for five days after cardiac arrest, but later regained consciousness very slowly, and by the 10 th day he was fully awake. The first EEG was recorded a few hours after cardiac arrest: it showed delta and theta activity of very low voltage. The next two EEGs, on the first and second day after cardiac arrest, showed virtually continuous activity of alpha frequency, which was most prominent frontally and with no reaction to stimulation. After the fourth day, the EEG again showed low voltage and increasing slow activity. The recordings taken after the patient was awake showed a tendency towards normal with diminishing delta activity, and increasing activity of theta and alpha frequencies. When re-examined 83 and 169 days after cardiac arrest the patient's EEG was normal. Psychological tests have demonstrated marked improvement. At present the patient shows severe impairment of recent memory and reduced attention, but his IQ is well above normal. The patient is able to manage at home, and is being rehabilitated.

\section{Case 2}

This patient, a 66 year old male, had his first EEG four days after cardiac arrest when he was still in coma. The EEG showed activity of alpha frequency with intermittent stage 2 sleep activity. After the sixth day he was fully awake and free from neurological sequelae. Twenty-three days later, after he had been discharged from the intensive care unit and transferred to a local hospital, he died from a further cardiac arrest.

\section{Case 3}

The third patient surviving coma with EEG showing alpha frequency, a 34 year old male, had his first EEG one day after cardiac arrest while he was still in coma. The record showed activity resembling alpha rhythm intermixed with slight theta activity. On the fifth day after cardiac arrest the EEG still showed activity of alpha frequency which was most prominent over the frontal areas and with no reaction on stimulation. On the eighth and tenth days the EEG showed increasing amounts of theta activity occurring in bursts separated by periods of apparent quiescense. Activity of alpha frequency was dominant again 12 and 14 days after the cardiac arrest. Fifteen days after the accident the patient gradually regained consciousness. After 28 days he was fully awake and his EEG showed normal alpha activity with minimal theta activity. He had only minimal neurological sequelae. He is now, two years after the cardiac arrest, managing at home with some assistance and showing only slight impairment of recent memory.

\section{Discussion}

EEG activity resembling alpha rhythm during coma has often been described in patients with brainstem lesions (Loeb and Poggio, 1953; Friedlander, 1959; Chatrian et al., 1964), but it is only recently that rhythm of alpha frequency has been described in the EEG of patients in coma after cardiac arrest. In 1965 Hockaday et al. mentioned that they had observed alpha rhythms in the EEGs of patients who were in coma after cardiac arrest. However, when these were recorded the patients were already recovering consciousness. Binnie et al. (1970) alluded to some patients with EEG rhythm of alpha frequency who died without having regained consciousness, while similar cases have been described by Brierley et al. (1971) and Prior (1973). 
Vignaendra et al. (1974), Sharbrough et al. (1975) and Westmoreland et al. (1975) described in great detail "alpha-coma" activity in patients after cardiac arrest, and emphasised that such a finding suggested an extremely bad prognosis because all their patients had died without regaining consciousness. Later Chokroverty (1975) described some cases of coma with EEG rhythms of alpha frequency after cardiac arrest who survived. Grindal and Suter (1975) also described similar surviving cases after high voltage accidents. None of these authors have compared the prognosis in patients with coma associated with alpha frequency rhythms in the EEC with a clinically similar group of individuals who had other EEG findings after cerebral anoxia from cardiac arrest. In our investigation we examined and compared the prognosis of 13 patients in coma with EEG rhythms of alpha frequency with the prognosis of 52 patients in coma from the same group who had other EEG patterns after cardiac arrest. We found not only a longer period of survival but also a higher incidence of recovery of consciousness among patients with alpha frequency EEG activity, than in the other group. Among all surviving patients the neurological sequelae were less severe in those patients who survived coma with EEG rhythms of alpha frequency. In spite of memory deficits these individuals were able to manage at home, whereas those surviving from the other group had to remain in hospital.

Our results suggest that the finding of EEG rhythms of alpha frequency during coma after cardiac arrest does not inevitably imply an extremely bad prognosis. In some comatose patients with alpha frequency EEG activity there was a transient deterioration of the EEG, but none developed isoelectric EEGs or clinical signs of brain death. Our experience does not, therefore, support the supposition of Westmoreland et al. (1975) that this EEG pattern represents one phase in a process of degradation.

\section{References}

Binnie, C. D., Prior, P. F., Lloyd, D. S. L., Scott, D. F., and Margerison, J. H. (1970). EEG prediction of fatal anoxic brain damage after resuscitation from cardiac arrest. British Medical Journal, 4, 265-268.

Brierley, J. B., Adams, J. H., Graham, D. I., and Simpson, J. A. (1971). Neocortical death after cardiac arrest. A clinical, neurophysiological and neuropathological report of two cases. Lancet, 2, 560-565.

Chatrian, G. E., White, L. E., and Shaw, C. M. (1964). EEG pattern resembling wakefulness in unresponsive decerebrate state following traumatic brain stem infarct. Electroencephalography and Clinical Neurophysiology, 16, 285-289.

Chokroverty, S. (1975). "Alpha-like" rhythms in EEGs in coma after cardiac arrest. Neurology (Minneapolis), 25, 655-663.

Friedlander, W. J. (1959). Electroencephalographic changes in acute brain stem vascular lesions. Neurology (Minneapolis), 9, 24-34.

Grindal, A. B., and Suter, C. (1975). “Alpha-pattern coma" in high voltage electrical injury. Electroencephalography and Clinical neurophysiology, 38, 521-526.

Hockaday, J. M., Potts, F., and Epstein, E. (1965). EEG changes in acute cerebral anoxia from cardiac or respiratory arrest. Electroencephalography and Clinical Neurophysiology, 18, 575-586.

Loeb, C., and Poggio, G. (1953). Electroencephalograms in a case with ponto-mesencephalic hemorrhage. Electroencephalography and Clinical Neurophysiology, 5, 295-296.

Pampiglione, G. (1962). Electroencephalographic studies after cardiorespiratory resuscitation. Pro- 8 ceedings of the Royal Society of Medicine, 55, 653.

Prior, P. F. (1973). The EEG in Acute Cerebrak Anoxia. Excerpta Medica: Amsterdam.

Sharbrough, F. W., Westmoreland, B., and Klass, D. W. (1975). The significance of sustained rhythmic EEG patterns in comatose patients following cardiopulmonary failure. Electroencephalography and Clinical Neurophysiology, 38, 100.

Vignaendra, V., Wilkus, R. J., Copass, M. K., and Chatrian, G. E. (1974). Electroencephalographic rhythms of alpha frequency in comatose patients after cardiopulmonary arrest. Neurology (Minneapolis), 24, 582-588.

Westmoreland, B. F., Klass, D. W., Sharbrough, F. W., and Reagan, T. J. (1975). "Alpha-coma" EEG, clinical, pathological and etiologic correlations. Archives of Neurology (Chicago), 32, 713-718. 